University of Nebraska - Lincoln

DigitalCommons@University of Nebraska - Lincoln

USDA National Wildlife Research Center - Staff Publications
U.S. Department of Agriculture: Animal and Plant Health Inspection Service

2018

\title{
Valuing the absence of feral swine in the United States: A partial equilibrium approach
}

\author{
J. J. Holderieath \\ Louisiana Tech University, jjhold@latech.edu \\ D. L. Pendell \\ Kansas State University, dpendell@k-state.edu \\ J. C. Hadrich \\ University of Minnesota, jhadrich@umn.edu
}

\author{
A. Anderson \\ USDA/APHIS/WS National Wildlife Resource Center \\ C. Slootmaker \\ USDA/APHIS/WS National Wildlife Resource Center
}

See next page for additional authors

Follow this and additional works at: https://digitalcommons.unl.edu/icwdm_usdanwrc

Part of the Life Sciences Commons

Holderieath, J. J.; Pendell, D. L.; Hadrich, J. C.; Anderson, A.; Slootmaker, C.; Harper, E.; and Shwiff, S. A., "Valuing the absence of feral swine in the United States: A partial equilibrium approach" (2018). USDA National Wildlife Research Center - Staff Publications. 2127.

https://digitalcommons.unl.edu/icwdm_usdanwrc/2127

This Article is brought to you for free and open access by the U.S. Department of Agriculture: Animal and Plant Health Inspection Service at DigitalCommons@University of Nebraska - Lincoln. It has been accepted for inclusion in USDA National Wildlife Research Center - Staff Publications by an authorized administrator of DigitalCommons@University of Nebraska - Lincoln. 


\section{Authors}

J. J. Holderieath, D. L. Pendell, J. C. Hadrich, A. Anderson, C. Slootmaker, E. Harper, and S. A. Shwiff 


\title{
Valuing the absence of feral swine in the United States: A partial equilibrium approach
}

\author{
J.J. Holderieath ${ }^{\mathrm{a}, *}$, D.L. Pendell ${ }^{\mathrm{b}}$, J.C. Hadrich ${ }^{\mathrm{c}}$, A. Anderson ${ }^{\mathrm{d}}$, C. Slootmaker ${ }^{\mathrm{d}}$, E. Harper ${ }^{\mathrm{d}}$, \\ S.A. Shwiff ${ }^{\mathrm{d}}$ \\ ${ }^{a}$ Louisiana Tech University, Department of Agricultural Sciences and Forestry, P.O. Box 10198, Ruston, LA 71272, USA \\ ${ }^{\mathrm{b}}$ Kansas State University, Department of Agricultural Economics, 220 Waters Hall, Manhattan, KS 66506, USA \\ ${ }^{\mathrm{c}}$ University of Minnesota, Department of Applied Economics, 218J Ruttan Hall, 1994 Buford Avenue, St. Paul, MN 55108-6040, USA \\ d USDA/APHIS/WS National Wildlife Research Center, 4101 Laporte Avenue, Fort Collins, CO 80521, USA
}

\section{A R T I C L E I N F O}

\section{Keywords:}

Crop damage

Equilibrium displacement model

Feral swine

Producer surplus

Consumer surplus

Wild pigs

\begin{abstract}
A B S T R A C T
Feral swine (also called wild pigs; Sus scrofa Linnaeus) are known to cause damage to crops among other types of property damage. This research addresses the lack of economic welfare estimates of wild pig imposed crop damages in the literature by estimating the value of wild pig removal with respect to five crops in nine southern U.S. states. An equilibrium displacement model was used to assess the changes in price and quantity that would result from eliminating damage to corn, soybeans, wheat, rice, and peanuts in these nine states. Changes in price and quantity were used to calculate the changes in producer and consumer welfare in both the short- and longrun. The total producer and consumer surplus gains were found to be $\$ 142$ million in the short-run and $\$ 89$ million in the long-run.
\end{abstract}

\section{Introduction}

Conflicts between humans and wildlife arise due to diverging interests between species. Those conflicts can range from property damage to threatening and predatory behavior (USDA APHIS, 2015). The United States devotes considerable financial resources to managing human-wildlife conflicts. In 2014, the USDA allocated \$106 million to the Wildlife Services division of the Animal and Plant Health Inspection Service (APHIS) for a portion of the federally-funded human-wildlife conflict mitigation efforts (USDA, 2015). Among policy makers and researchers interested in human-wildlife conflicts, one species of particular recent interest is feral swine (also called wild pigs; Sus scrofa Linnaeus). The USDA has allocated $\$ 20$ million to support the goal to "eliminate feral swine from two States [sic] every three to five years and stabilize feral swine damage within 10 [sic] years" (Bannerman and Cole, 2014).

Spanish Conquistadors introduced wild pigs in the southeastern United States and California in the sixteenth century as well as by Polynesians to Hawaii in the fourth or fifth century (Kirch, 1982; Mayer and Brisbin, 2008; Mann, 2006). By 1982, wild pigs were present in 699 counties in 19 states, primarily in the southeastern United States (Mayer and Brisbin, 2008). Over the next 30 years, wild pigs spread at an accelerated rate, affecting 1323 counties in 39 states (Lutman, 2013;
Bevins et al., 2014). The 624 counties into which wild pigs moved between 1982 and 2012 comprised a land area of approximately 1.9 million square kilometers, which is more than the combined land area of Texas, California, Montana, and New Mexico.

Feral swine are known to cause damage to crops and other types of property. A recent survey reported by Anderson et al. (2016) found a production loss of nearly $\$ 190$ million in eleven states from just six of the crops grown in those states. This survey result is important, as it demonstrates the size of the crop that wild pigs have prevented reaching the market.

Production losses are only part of the overall impact caused by wild pigs. Preventing commodities from reaching the market restricts supply, resulting in higher equilibrium prices for consumers. In the absence of wild pig imposed damage, market supply would increase resulting in a downward push on prices. Unequivocally, consumers would be better off as they would enjoy more of these commodities at a lower price; however, the outcome for producers is less obvious. Producers experiencing the reduction in damage would be better off only if the increase in crop quantities made up for the lower prices. Producers who would not see an increase in production would be worse off. These changes in the wellbeing of consumers and producers are known as welfare changes. To date, the authors are unaware of any studies that assess the welfare implications of wild pig crop damage.

\footnotetext{
* Corresponding author.

E-mail addresses: jjhold@latech.edu (J.J. Holderieath), dpendell@k-state.edu (D.L. Pendell), jhadrich@umn.edu (J.C. Hadrich).
} 
To address this gap in the literature, this study estimated the economic impact of wild pig damage in nine Southeastern states on U.S. crop producers and consumers of corn, soybeans, wheat, rice, and peanuts. Specifically, this research estimated changes in producer and consumer welfare by calculating the changes in price and quantity implied by assuming the previously destroyed commodities now enter into the market. Changes in price and quantity were used to calculate the change in producer and consumer welfare.

A partial equilibrium model is presented in the next section based on historical U.S. production data from USDA National Agricultural Statistics Service (NASS) and wild pig presence data and damage estimates from Anderson et al. (2016) with more details in Holderieath (2017). The result of this model depicts a scenario free of wild pig associated crop damage to contrast with the current reality of wild pig imposed damage. This approach follows Elser et al. (2016) by placing an economic value of managing birds in U.S. sweet cherry production. It stands to reason that the difference in welfare measures between the model result and the current reality of damage is the value of removal with respect to these five crops in these nine states.

\section{Materials and methods}

Building on previous wild pig damage literature, this analysis examines the impacts through market linkages of an exogenous shock comprised of hypothetical removal of wild pig associated damage. Wild pig associated crop damage is primarily incurred at the farm level and the end use of the crop is indistinguishable at this level. These factors led to the producer selling output at the farm gate serving as the primary market of concern for this work. One commonly used framework for measuring the quantity and price effects due to shocks such as this is an equilibrium displacement model (EDM).

The EDM is a linear abstraction of supply and demand functions that describe the transition from one equilibrium to another (Wohlgenant, 1993, 2011). The EDM is a system of logged and totally differentiated supply and demand equations where the change in quantity supplied and change in quantity demanded are functions of own and cross prices, elasticities, and an exogenous shock. Provided a relatively small exogenous supply shock, current prices and quantities, and elasticities, the EDM can be used to calculate the new price and quantity equilibrium resulting from the change in supply due to an elimination of wild pig crop damage. Those price and quantity changes are then used to geometrically measure the changes in producer and consumer surplus (welfare changes).

First, supply and demand functions are derived for each commodity in the EDM. The EDM used in this study is fully documented in Holderieath (2017). A. Second, the exogenous production shocks were incorporated into the EDM, and changes in price and quantity were obtained. Third, producer and consumer welfare were calculated and used to evaluate the changes in welfare resulting from a reduction in wild pig damage.

This analysis considers five commodities: corn, soybeans, wheat, rice, and peanuts. Grain sorghum was not included, as it was only reported by Anderson et al. (2016) for one state, and Missouri and California were not included as they did not have sufficient responses in the five commodities of interest to report damages. Five sets of supply and demand equations make up the EDM used in this analysis. Change in quantity demanded for each commodity, $k$, is a function of its own change in price and its own price elasticity of demand. Similarly, changes in quantity exported and imported of commodity $k$ are a function of their respective elasticities and the price change of commodity $k$.

Two regions ( $\omega$ ) supply the commodities to the market, the region with the reduction in wild pig damage (WPR) and all other states (AOS). Supply for all commodities in each region, except peanuts, are a function of each own price elasticity of supply for the same region, the change in price of commodity $k$ as well as the respective cross price elasticities and price changes of commodity where $j \neq k$. Change in quantity supplied of peanuts for each region is a function only of the own price elasticity and the change in price of peanuts. Supply equations for the WPR region also include an additive change due to the exogenous production shock. In this research, we considered an exogenous shock as the increase in quantity present in the market due to the reduction of wild pig damage.

Elasticities can be obtained from past literature, "guestimated," or estimated (James and Alston, 2002). "Guestimated" elasticities often take the form of unit elasticities (Sumner, 2007; Harrington and Dubman, 2008). For this study, a mixed strategy is employed. Supply, import, and export elasticities come from previously published studies or are set to a value consistent with previous literature. Demand elasticities were estimated using the Almost Ideal Demand System (AIDS) developed by Deaton and Muellbauer (1980). These elasticities were estimated because a single source for all the demand elasticities in the system was not available. The set of elasticities used in this study is presented in Holderieath (2017) along with their sources.

Each commodity destination and source is linked together into a single equilibrium condition that considers weights of each destination and source. These weights function as limiting terms that prevent a very small portion of a market from disproportionately impacting the larger market and are discussed in Holderieath (2017). The efficency in price transmission exhibited in these five markets allowed a single price to be assumed for consumers, exports, imports and in both production regions. The five equilibrium conditions were solved simultaneously for change in price and then change in price was substituted into each demand, supply, import, and export equation to find quantity changes.

Exogenous production shocks $\left(E B_{k, \omega}\right)$ were derived from estimates of damage for each of the nine U.S. states (States) as reported by Anderson et al. (2016). Anderson et al. (2016) (see Table 1) presents the amount of each crop that would be present in the absence of wild pigs $\left(\right.$ Damage $\left._{k}^{\text {State }}\right)$. Pre-shock production (Production ${ }_{k}^{\text {State }}$ ) was the total reported production in each state by USDA National Agricultural Statistics Service (USDA NASS, 2015). The exogenous production shock is calculated as follows:

$E B_{k, \omega}=\frac{\sum_{\text {States }}\left(\text { Damage }_{k}^{\text {State } *} \text { Production }_{k}^{\text {State }}\right)}{\sum_{\text {States }} \text { Production }_{k}^{\text {State }}} \times 100$.

We assume that wild pigs are instantly and permanently removed from nine Southeastern U.S. states to demonstrate potential gains from elimination of wild pig related crop damage with respect to these five crops in these nine states. The wild pig removal states are Alabama, Arkansas, Florida, Georgia, Louisiana, Mississippi, North Carolina, South Carolina, and Texas. California and Missouri were omitted from this study due to low survey coverage in Anderson et al. (2016). This scenario is used to find a value of removal in these nine states with respect to these five crops. The calculated production shocks represent an increase of $1.47 \%, 0.50 \%, 1.66 \%, 0.46 \%$, and $1.80 \%$ in corn, soybeans, wheat, rice, and peanuts, respectively, in the WPR region.

Table 1

Percent of crop lost to wild pigs by state (\%). Source: Anderson et al. (2016).

\begin{tabular}{llllll}
\hline State & Corn & Soybeans & Wheat & Rice & Peanuts \\
\hline Alabama & 0.93 & 1.38 & 0.62 & NA & 6.17 \\
Arkansas & 1.09 & 0.27 & 0.75 & 0.27 & NA \\
Florida & 4.41 & 3.43 & NA & NA & 1.84 \\
Georgia & 4.73 & 1.07 & 4.39 & NA & NA \\
Louisiana & 0.83 & 0.74 & 0.94 & 1.26 & NA \\
Mississippi & 1.34 & 0.4 & 0.7 & 0.12 & NA \\
North Carolina & 0.38 & 0.09 & 0.15 & NA & 0.49 \\
South Carolina & 1.59 & 1.52 & 1.71 & NA & NA \\
Texas & 1.65 & 1.1 & 3.05 & 2.46 & 9.28 \\
\hline
\end{tabular}

NA is not applicable. 
Table 2

Relative price and quantity changes induced by wild pig removal (\%).

\begin{tabular}{|c|c|c|}
\hline & Short-Run & Long-Run \\
\hline \multicolumn{3}{|c|}{ Relative Price Changes } \\
\hline Corn & -0.080 & -0.032 \\
\hline Soybeans & -0.027 & -0.017 \\
\hline Wheat & -0.150 & -0.046 \\
\hline Rice & -0.130 & -0.053 \\
\hline Peanuts & -2.110 & -0.430 \\
\hline \multicolumn{3}{|c|}{ Relative Change in Quantity Supplied From the $A O S^{\mathrm{a}}$ Region } \\
\hline Corn & -0.013 & -0.043 \\
\hline Soybeans & 0.010 & 0.009 \\
\hline Wheat & -0.015 & -0.015 \\
\hline Rice & -0.013 & -0.027 \\
\hline Peanuts & -0.740 & -0.820 \\
\hline \multicolumn{3}{|c|}{ Relative Change in Quantity Supplied From the $W P R^{\mathrm{b}}$ Region } \\
\hline Corn & 1.450 & 1.390 \\
\hline Soybeans & 0.510 & 0.510 \\
\hline Wheat & 1.620 & 1.590 \\
\hline Rice & 0.400 & 0.340 \\
\hline Peanuts & 1.060 & 0.980 \\
\hline \multicolumn{3}{|c|}{ Relative Change in Quantity Demanded } \\
\hline Corn & 0.056 & 0.029 \\
\hline Soybeans & 0.014 & 0.012 \\
\hline Wheat & 0.031 & 0.049 \\
\hline Rice & 0.020 & 0.036 \\
\hline Peanuts & 0.500 & 0.410 \\
\hline
\end{tabular}

a AOS, All Other States Region.

b WPR, Wild Pig Removal States including Alabama, Arkansas, Florida, Georgia, Louisiana, Mississippi, North Carolina, South Carolina, and Texas.

Consumer surplus represents the benefit consumers receive from the purchase of a product above what is paid for the product in monetary terms while producer surplus represents the amount received from the sale of a product above its marginal cost. This research follows Brester et al. (2004) and calculates the change in welfare geometrically. The accuracy of using a linear approximation for estimation of the change in producer and consumer surplus depends on the relative size of the shift and the degree of non-linearity in the true supply and demand functions (Brester et al., 2004; Pendell et al., 2010; Wohlgenant, 2011).

\section{Results}

The instantaneous removal of wild pig related crop damage results in the additional supply of each commodity available on the market; thus, most short-run commodity prices decreased by a small amount (Table 2). The one exception is the change in the price of peanuts, which fell by $2.11 \%$. This is because $97.22 \%$ of peanuts are grown in the WPR region, and peanuts usually experienced the most intense damage among states reporting damage (Anderson et al., 2016). As expected, long-run changes in prices were smaller when compared to the short-run because producers and consumers are able to shift to other commodities for production and consumption purposes.

Lower commodity prices lead to a small increase in the quantity demanded of each of the commodities. In the WPR region, supply increases for all the commodities as we remove wild pigs. The increase in quantity was slightly smaller than the exogenous shock, as producers were reacting to the lower price as well as experiencing higher production with the absence of wild pigs. In the AOS region, supply of corn, wheat, and rice all decreased by $0.01 \%$ in the short-run, and $0.04 \%, 0.01 \%$, and $0.02 \%$, respectively, in the long-run. Peanuts quantity fell by $0.74 \%$ and $0.79 \%$ in the short- and long-run, respectively. Soybean prices were less impacted than other commodities which led to increased soybean production by $0.01 \%$ in both the shortand long-run.

The key difference between the short- and long-run is that producers
Table 3

Changes in producer and consumer surplus due to wild pig removal (million \$).

\begin{tabular}{|c|c|c|c|}
\hline $\begin{array}{l}\text { Short-run change } \\
\text { in: }\end{array}$ & Consumer Surplus & $\begin{array}{l}\text { Producer } \\
\text { Surplus } \\
\text { (AOS Region) }\end{array}$ & $\begin{array}{l}\text { Producer Surplus } \\
\text { (WPR Region) }\end{array}$ \\
\hline Corn & 46.571 & -42.044 & 45.509 \\
\hline Soybeans & 13.231 & -5.498 & 28.882 \\
\hline Wheat & 19.650 & -15.926 & 18.938 \\
\hline Rice & 4.372 & -0.893 & 8.907 \\
\hline Peanuts & 25.182 & -0.698 & -3.944 \\
\hline Total & 109.005 & -65.058 & 98.293 \\
\hline \multicolumn{3}{|c|}{ Net change in surplus } & 142.239 \\
\hline Long-run change in: & Consumer Surplus & $\begin{array}{l}\text { Producer } \\
\text { Surplus } \\
\text { (AOS Region) }\end{array}$ & $\begin{array}{l}\text { Producer Surplus } \\
\text { (WPR Region) }\end{array}$ \\
\hline Corn & 18.060 & -11.558 & 14.048 \\
\hline Soybeans & 8.314 & -0.297 & 29.631 \\
\hline Wheat & 5.415 & -1.012 & 9.906 \\
\hline Rice & 1.754 & -0.163 & 3.755 \\
\hline Peanuts & 5.018 & -0.139 & 6.252 \\
\hline Total & 38.560 & -13.169 & 63.592 \\
\hline \multicolumn{3}{|c|}{ Net change in surplus } & 88.983 \\
\hline
\end{tabular}

and consumers are able to adjust their production or consumption in the long-run because factors of production and consumption are not fixed over time. Most corn, soybeans, and wheat produced in the United States are not grown in the removal region. Net welfare changes, the sum of consumer surplus change and the two producer surplus changes, in corn were the largest ( $\$ 50$ and $\$ 21$ million, in the short- and longrun, respectively), even though most corn production takes place outside of the removal region (Table 3). Corn is a major crop in the United States, and as such, a small change in price has large welfare effects. Soybeans are also a major U.S. crop with substantial welfare effects (\$37 and \$38 million in the short- and long-run, respectively) from a small price change. Net effects of wheat are $\$ 23$ and $\$ 14$ million in the short- and long-run, respectively. Over $75 \%$ of rice is grown in the WPR region; however, the exogenous shock is only $0.46 \%$. The resulting price changes to rice only change welfare by $\$ 12$ and $\$ 5$ million in the short- and long-run, respectively. Over $97 \%$ of peanuts are grown in the WPR region, and the exogenous shock was calculated at $1.80 \%$, leading to welfare effects at $\$ 21$ and $\$ 11$ million, in the short- and long-run, respectively.

Short- and long-run changes in consumer surplus were positive by $\$ 109$ and $\$ 39$ million, respectively. This increase in consumer surplus was due to the lower commodity prices. Long-run changes are smaller in magnitude than short-run because of the increased elasticity implied by a greater ability to adapt over longer periods of time. Producer surplus in the AOS region was a net loss of $\$ 65$ million and \$13 million, in the short- and long-run, respectively. Producer surplus in the WPR region was a net gain of \$98 million and $\$ 64$ million, in the short- and long-run, respectively. An elimination of wild pig related crop damage in these nine states will result in a net surplus gain of approximately $\$ 142$ million immediately and $\$ 89$ million in the long-run.

This change in surplus is lower than might be expected given the work of Pimentel et al. (2005), Higginbotham et al. (2008) and Mengak (2012). However, the scope of Pimentel et al. (2005) was much wider as an estimate of nationwide damage across substantially more types of property. Both Higginbotham et al. (2008) and Mengak (2012) covered more types of losses (e.g. fixed assets, timber, and crops excluded from this analysis) in a more limited area. Anderson et al. (2016) covered more crops and states, but did not address the market component of wild pig impact. As estimates at a point in time, these studies do not consider the market responses and kinds of adaptations that producers will take due to changes in market prices. It is important to note the 
substantial surplus losses for producers outside of the removal region, and this is the first analysis to investigate that impact in this context.

\section{Conclusions}

Wild pigs inflict destruction in terms of damage, predatory behavior, and disease transmission. For this study, we are particularly concerned about the destruction wild pigs cause to crops. Simply valuing the crops that are destroyed is an inadequate measure of impact, because it does not take into account market impacts due the reduction in supply of those crops. To estimate the value of the absence of wild pigs with respect to crop damage, estimates of the crop damage were used in an equilibrium displacement model to calculate the changes in price and quantity that would result from elimination of wild pig related crop damage in nine Southeastern U.S. states.

A net surplus gain in both the short and long-run of $\$ 142$ million and $\$ 89$ million, respectively, show that wild pigs inflict significant damage on producers and consumers of corn, soybeans, wheat, rice, and peanuts. As expected, long-run welfare effects were smaller due to the ability of producers and consumers to adapt to price changes of commodities over time. Producers and consumers will enjoy the benefits of wild pig removal annually at a rate of between $\$ 142$ million and $\$ 89$ million per year, with the welfare effects decreasing across time. It is also important to consider the distribution of the losses. Most of the short-run welfare losses to the states not benefiting from wild pig removal would be borne by corn producers, and that loss would amount to nearly 12.99 USD per metric ton in 2014 production.

There are two primary limitations to the current results to be addressed in future research. First, there are other potential and actual costs imposed by wild pigs that are not covered in the analysis, such as removal costs and additional crops not covered in this analysis. Second, the short-run changes represent the within-season benefits and costs of immediately reducing damage. The long-run changes represent the impact on a timescale when producers and consumers are able to fully adapt to the change in price expected from the restoration of the damaged goods to market. The exact duration of the transition from shortto long-run is unknown, but is generally understood to be less than ten years. The periods between each equilibrium, and how those benefits and costs are distributed, may be of interest to policy makers. The uncertainty about short-to long-run transitions is why the welfare effects are stated in a range. The estimates provided by this paper provides an idea of the impact of wild pig damage to evaluate potential management activities.

\section{Acknowledgements}

Financial support was provided by National Wildlife Research Center (USDA APHIS NWRC).

\section{References}

Anderson, A., Slootmaker, C., Harper, E., Holderieath, J., Shwiff, S.A., 2016. Economic estimates of feral swine damage and control in 11 US states. Crop. Prot 89, 89-94. http://dx.doi.org/10.1016/j.cropro.2016.06.023.

Bannerman, C., Cole, L., 2014. News Release: USDA Announces \$20 Million Effort to Reduce Damage Caused by Feral Swine. Riverdale. U.S. Department of Agriculture, APHIS, Maryland.

Bevins, S.N., Pedersen, K., Lutman, M.W., Gidlewski, T., Deliberto, T.J., 2014. Consequences associated with the recent range expansion of nonnative feral swine. Bioscience 64 (4), 291-299. http://dx.doi.org/10.1093/biosci/biu015.

Brester, G.W., Marsh, J.M., Atwood, J.A., 2004. Distributional impacts of country-oforigin labeling in the U.S. meat industry. J. Agric. Resour. Econ. 29 (2), 206-227.

Deaton, A., Muellbauer, J., 1980. An Almost ideal demand system. Am. Econ. Rev. 70 (3), $312-326$.

Elser, J.L., Anderson, A., Lindell, C.A., Dalsted, N., Bernasek, A., Shwiff, S.A., 2016. Economic impacts of bird damage and management in U.S. sweet cherry production. Crop. Prot 83, 9-14. http://dx.doi.org/10.1016/j.cropro.2016.01.014.

Harrington, D.H., Dubman, R., 2008. Equilibrium displacement mathematical Programming models methodology and a model of the U.S. Agricultural sector. U.S. Department of Agriculture, Economic Research Service, Washington DC.

Holderieath, J.J., 2017. Essays on Feral Swine: Producer Welfare Effects and Spatiotemporal Management of Feral Swine. PhD diss. Colorado State University. https://hdl.handle.net/10217/185638.

Higginbotham, B.J., Clary, G., Hysmith, L., Bodenchuk, M., 2008. Statewide Feral Hog Abatement Pilot Project, 2006-2007. Texas AgriLife Extension Service.

James, J., Alston, J., 2002. Taxes and quality: a market-level analysis. Aust. J. Agric. Resour. Econ. 46 (3), 417-445. http://dx.doi.org/10.1111/1467-8489.00186.

Kirch, P.V., 1982. The impact of the prehistoric Polynesians on the Hawaiian ecosystem. Pac. Sci. 36 (1), 1-14.

Lutman, M.W., 2013. Dataset: Feral Swine Presence. U.S. Department of Agriculture, Animal and Plant Health Inspection Service. Wildlife Services. National Wildlife Research Center, Fort Collins, CO.

Mann, C.C., 2006. 1491: New Revelations of the Americas before Columbus. Vintage Books, New York.

Mayer, J.J., Brisbin, I.L., 2008. Wild Pigs in the United States: Their History, Comparative Morphology, and Current Status. University of Georgia Press.

Mengak, M.T., 2012. 2012 Georgia Wild Pig Survey. Final Report. Warner School of Forestry and Natural Resources, University of Georgia, Athens, GA.

Pendell, D.L., Brester, G.W., Schroeder, T.C., Dhuyvetter, K.C., Tonsor, G.T., 2010. Animal identification and tracing in the United States. Am. J. Agric. Econ. 92 (4), 927-940. http://dx.doi.org/10.1093/ajae/aaq037.

Pimentel, D., Zuniga, R., Morrison, D., 2005. Update on the environmental and economic costs associated with alien-invasive species in the United States. Ecol. Econ. 52 (3), 273-288. http://dx.doi.org/10.1016/j.ecolecon.2004.10.002.

Sumner, D.A., 2007. Boxed. In: Conflicts between U.S. Farm Policies and WTO Obligations. CATO Institute.

USDA, 2015. FY 2016 Budget Summary and Annual Performance Plan. U.S. Department of Agriculture, Office of Budget and Program Analysis, Washington D.C.

USDA APHIS, 2015. Wildlife Services protects resources. Available at: http://1.usa.gov/ 1QBwwFI, Accessed date: 26 October 2015.

USDA NASS, 2015. USDA/NASS QuickStats Ad-hoc query tool. Available at: http:// quickstats.nass.usda.gov.

Wohlgenant, M.K., 2011. Consumer demand and welfare in equilibrium displacement models. In: Lusk, J.L., Roosen, J., Shogren, J.F. (Eds.), The Oxford Handbook of the Economics of Food Consumption and Policy. Oxford University Press, pp. 292-318. http://dx.doi.org/10.1093/oxfordhb/9780199569441.013.0012.

Wohlgenant, M.K., 1993. Distribution of gains from research and promotion in multistage production systems: the case of the U.S. Beef and pork industries. Am. J. Agric. Econ. 75 (3), 642-651. 